\title{
THE DISTRIBUTION AND EVOLUTION OF INDICA- TORS OF HOSPITAL MORBIDITY AND MORTALITY FOR THYROID CANCER IN BRAZIL
}

\author{
Danielle Freitas Sales*, Caroline Alves Feitosa** \\ Corresponding author: Danielle Freitas Sales - daniellesales12.1@bahiana.edu.br \\ *BAHIANA - School of Medicine and Public Health (EBMSP) \\ **BAHIANA - School of Medicine and Public Health(EBMSP). Institute of Collective Health - Federal University \\ of Bahia (ISC/UFBA)
}

\begin{abstract}
A B S T R A C T
Introduction: Thyroid cancer is the most common endocrine neoplasm, representing approximately $1 \%$ of all malignant tumors in western countries. It is three times more common in women than in men. Aims: To analyze the changes in the rates of hospital morbidity and mortality from thyroid cancer in Brazil during the period from 2000 to 2012 . Methods: This is an ecological study, with data from the Brazilian Health Information Systems. Data regarding hospital morbidity and mortality from thyroid cancer (CID 10 C73) were collected as well as variables such as schooling, ethnicity and age group. Results: This study identified 39,191 hospitalizations for thyroid cancer and 6,914 deaths from the same cause in the period investigated, with the occurrence and deaths much higher in women. Furthermore, the number of cases is also greater in subjects with incomplete basic schooling, and among individuals aged between 40-49 years. Discussion: The findings are supported by other studies, although some of the characteristics of the patients have never been evaluated previously. Conclusion: Over the 13 year period assessed, there was an increase in the rates of hospital morbidity and mortality from thyroid cancer for both men and women in Brazil. More research on this subject is needed as well as health policies to increase awareness of the population about thyroid cancer and improve access to health services.
\end{abstract}

Keywords: Thyroid cancer; Mortality; Incidence; Risk factors. 


\section{INTRODUCTION}

Thyroid Cancer (TC) is the most common cancer in the endocrine system, accounting for approximately $1 \%$ of all malignant tumors in western countries. Among the human cancer types, thyroid cancer has the highest growing incidence rate in women, and second highest incidence rate among man'. Despite being the most common endocrine system ailment, it is still considered a rare tumor in most parts of the world ${ }^{2}$ and is three times more common in women ${ }^{3}$.

Malignant thyroid tumors are classified according to histological type and can be arranged as differentiated (papillary, follicular - including socalled Hurthle cell carcinoma and medullary) and undifferentiated (or anaplastic) ${ }^{4,5}$. The biological development of TC can vary, ranging from low potential to high potential forms, extremely aggressive and lethal ${ }^{6,7}$. Differentiated carcinomas are responsible for $90 \%$ of cases of thyroid cancer, and when diagnosed early they are curable. In such cases, there is a good prognosis and long survival rates, similar to people who never had cancer, in more than $80 \%$ of cases ${ }^{8}$. However, anaplastic cases are highly lethal. It is estimated that there is a global survival rate of $95 \%$ for papillary carcinomas, $77 \%$ for follicular carcinomas as $85 \%$ for medullary carcinomas with negative lymph nodes, however, only $40 \%$ for carcinomas with ganglion invasion (positive lymph nodes) 9 .

The GLOBACAN project ${ }^{10}$ estimated 141,013 new cases of TC in the world and 35,573 deaths in 2002. The standardized incidence of TC was 5.5 new cases per 100,000 women in developed regions and 2.6 in developing areas (Africa and South America). Concerning the mortality, there were 0.5 deaths per 100.000 women in the developed regions and 0.8 in developing regions. On the other hand, among men, the mortality rate was the same in both regions $(0.4 / 100,000)^{9}$.

The risk factors for TC include exposure to ionizing radiation ${ }^{11}$, obesity ${ }^{12}$, altered levels of iodine in the diet $^{13}$, history of benign thyroid disease, such as benign nodules and goiter, adenomas ${ }^{14}$, the use of birth control pills, hormone replacement therapy and reproductive factors ${ }^{15}$. There are two hypotheses to account for the changing incidences, the first is that this increase in incidence is the result of the expanded use of diagnostic practices, such as ultrasound and fine needle biopsy and the other is that there is an association with a number of risk factors, including age, gender, ethnicity and geographical location ${ }^{16}$.

A study conducted in Brazil identified and estimated 6,066 new cases of thyroid cancer in 2006 , including 1,065 male cases and 5,001 female cases. For both, there was an increase in these rates with age, especially over 30 years. The incidence rates were also higher in women ${ }^{16}$. Another study carried out in Brazil identified lower mortality among young adults, with no gender difference. However, among mature adults and the elderly there was an increased mortality, significantly higher in females, with more than $70 \%$ of the deaths occurring in elderly 160 years or more), regardless of gender ${ }^{8}$.

Access to information on the incidence of cancer is essential to define the role of the risk factors and set priorities in prevention, planning, and administration of health services. However, this information is rarely available at national or regional level ${ }^{16}$.

In view of the shortage of recent information about the incidence and mortality of thyroid cancer in Brazil, it is necessary to further study and describe the changes in the indicators of morbidity and mortality. An analysis of the associations between cancer and risk factors can improve cancer diagnosis and prognostics, as well as reorient policies about preventive measures. Thus, the aim of this article is to analyze the changes in and geographical distribution of the indicators hospital morbidity and mortality from thyroid cancer in Brazil from 2000 to 2012 , according to gender and age group.

\section{METHODS}

This is an epidemiological study with an ecological design using aggregated data. The unit of analysis is the set of cases with respect to space and time ${ }^{17}$. The secondary data used in the research were collected 
at the Health Information Systems, including DATASUS - Department of Informatics of the Brazilian Unified Health System (SUS in the Brazilian Portuguese acronym) and INCA - National Cancer Institute (in the Brazilian Portuguese acronym), which are a set of integrated and articulated components designed to obtain, select and transform data into information ${ }^{18}$.

This project collected data on hospital morbidity and mortality from thyroid cancer (CID $10 \mathrm{C73}$ ), using the Hospital Cancer Registry (RHC), and data from the Brazilian Institute of Geography and Statistics and Mortality Information System (SIM). The RHC collects and stores data generated at cancer health services $^{19}$. SIM is a system created by DATASUS for obtaining regular data on mortality in the country ${ }^{20}$.

The variables examined in the study were age, gender, ethnicity, geographic distribution, education, family history of cancer, personal history of alcohol use and smoking. The indicators of morbidity and mortality were compared to these variables in the period from 2000 to 2012. The analysis of the changes and distribution of the cancer was performed using line graphs and tables with data, which allowed the comparison of this information and characterization of cases in relation to indicators over 13 years in Brazil.

The first step was the collection and tabulation of data in information system platforms DATASUS and INCA. The first data collected were the relative mortality rates for each year in Brazil and in each of the regions broken down by gender. These data were exported from the atlas of cancer provided by DATASUS and then were exported to Microsoft Office Excel 2007 platform, where the graphics and tables were made. Hospital morbidity data and variables were collected from the RHC provided by INCA, and then exported to Microsoft Office Excel 2007 and organized into charts and tables.

The calculation of the mortality rate was done automatically by the INCA data platform. The hospital morbidity rate was calculated dividing the number of hospitalizations by the total population. The result was multiplied by 100,000 , and rates were presented according to gender and region. In both cases, missing values were ignored.

The data used in this project are in the public domain, they were collected, organized and provided by the Brazilian government in aggregated and anonymized datasets. Thus, access to the data maintains the privacy of individuals. The analysis of secondary data is widely diffused in health research ${ }^{18}$ and its use does not require approval from the Committee of Ethics in Research in Humans (CEP).

\section{RESULTS}

This study identified 39,191 hospitalizations for thyroid cancer and 6,914 deaths from thyroid cancer in Brazil during the period from 2000 to 2012.

Table 1 shows details regarding the thyroid cancer cases. With respect to schooling, most thyroid cancer cases occur in individuals with incomplete Elementary schooling $(22 \%)$, followed by people who finished High School (19\%), those who had been to university $(12 \%)$ and Elementary complete $(11 \%)$, however, the largest number recorded are the cases with no information $(31 \%)$. With regard to ethnicity, most cases were found to be among individuals of white ethnicity $(31 \%)$, followed by mixed $(28 \%)$ and only $2 \%$ are reported as black. Once again, there was a high percentage of records with missing information (39\%).

According to the table 1, a quarter of thyroid cancer cases is of people aged between 40-49 years $(24 \%)$. In addition, $21 \%$ of the cases were aged 50-59 years and 20\%, 30-39 years. There was a small number of cases in the 60-69 group and 2029 years, $13 \%$ and $12 \%$ respectively.

With respect to a history of consumption of alcohol and tobacco consumption, both variables had a similar percentage, $31 \%$ of individuals had never used any of these substances and only $5 \%$ claimed to be regular consumers of alcohol and $6 \%$ of tobacco. In both cases, there was a high percentage of cases without information, $62 \%$ (24,389 cases) for the consumption of alcohol and $61 \%(23,977$ cases) for tobacco consumption.

Seventeen percent of cases have no history of cancer in the family and $10 \%$ have a history of any type of cancer in the family. There were many cases with 
missing information for this variable, $73 \%(28,456)$ of cases had no information.

Table 1. Characteristics of thyroid cancer hospitalizations in Brazil, 2000 to 2012.

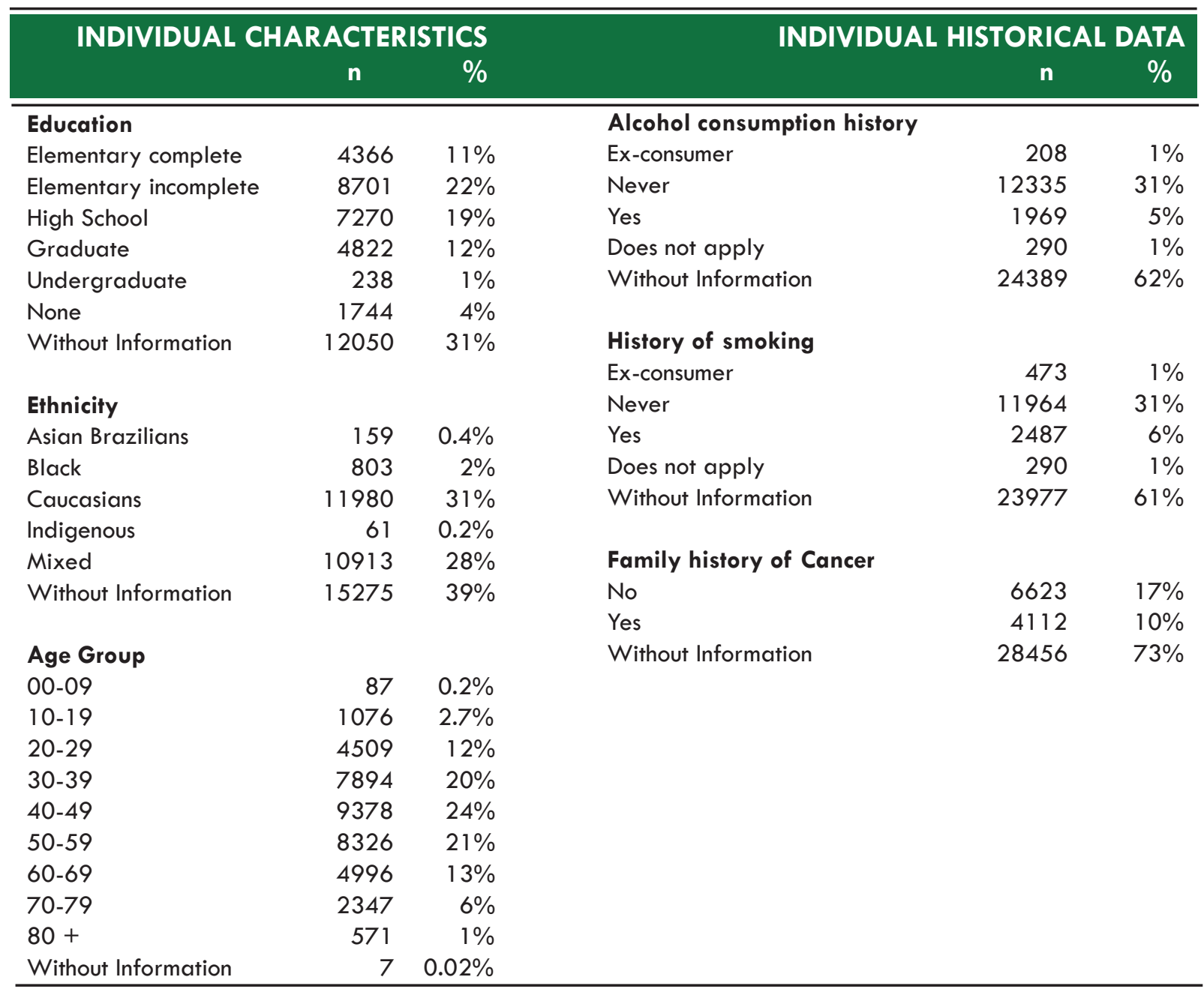

With respect to the types of thyroid cancer, we found that $41.8 \%(16,386)$ of the cases are follicular, while $51.07 \%(20,015)$ are papillary. A small percentage of the cases are medullary $(2.34 \%)$ and anaplastic $(1.39 \%)$. There was a small number of cases that were mixed medullary and papillary or follicular $(0.01 \%$ and $0.03 \%$, respectively). On the other hand, there are cases with no classification or with unavailable data (3.35\%) (see Table 2).

Table 2. Histological characteristics of thyroid cancer hospitalizations in Brazil, 2000 to 2012.

\begin{tabular}{lrr}
\hline \multicolumn{1}{c}{ Histological types } & $\mathbf{n}$ & $\%$ \\
\hline Follicular & & \\
Papillary & 16386 & $41.81 \%$ \\
Medullary & 20015 & $51.07 \%$ \\
Anaplastic/Undifferentiated & 917 & $2.34 \%$ \\
Mixed Medullary + Papillary & 544 & $1.39 \%$ \\
Mixed Medullary + Folicullar & 4 & $0.01 \%$ \\
Others (sclerosing, trabecular, not specified) & 11 & $0.03 \%$ \\
Undefined classification/Not available data & 102 & $0.26 \%$ \\
\hline
\end{tabular}

In Graph 1, it is possible to notice that there was a sharp growth in the number of hospital admissions in the year $2010(384 \%)$, with a steeper drop in the years 2011 and 2012.

We found a large discrepancy between genders, with a higher rate among females. The female hospital 
morbidity rate was 4 times higher than the male rate in the year 2000 (0.90 and 0.22 hospitalizations every 100,000 inhabitants, respectively). This was 5 times higher in the year 2010 (4.57 and 0.90/100,000, respectively), the year with the highest hospital morbidity in both genders.

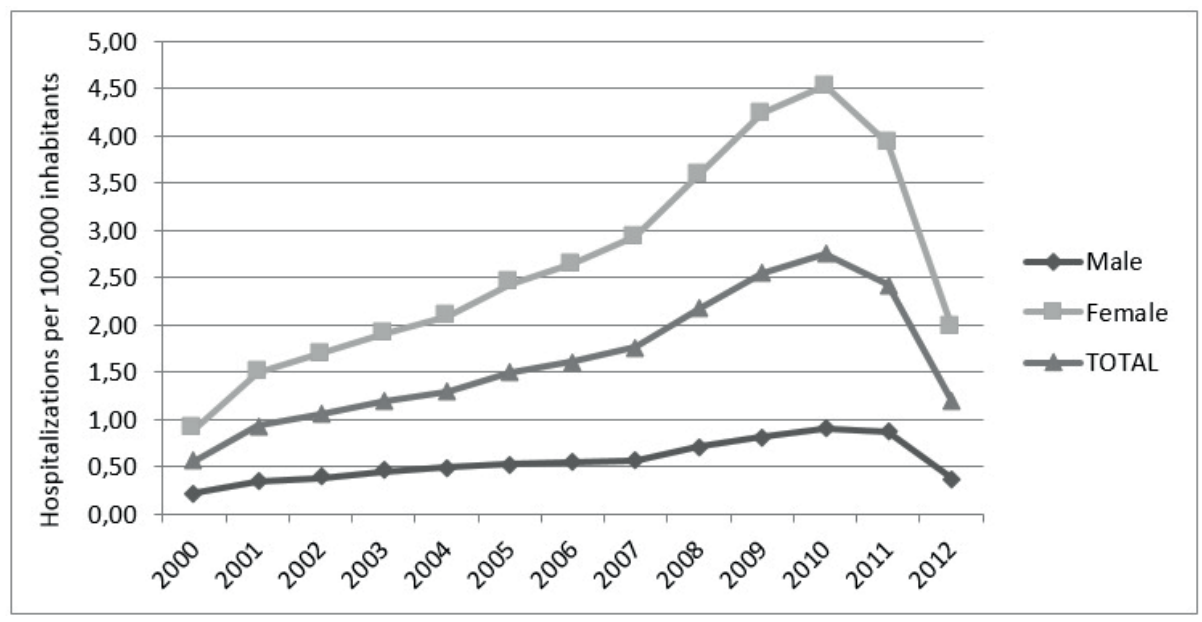

Graph 1. Hospital Morbidity rate from thyroid cancer by gender in Brazil between 2000 and 2012.

According to Graph 2, a moderate and steady growth of hospital morbidity between 2000 and 2007 can be seen. During this period, the Southeast region had the highest rates, while the other regions varied. From 2008, the Northeast and Southeast regions showed a sharp increase in the hospital morbidity rate. In the year 2009 and 2010 in addition to these, there was a significant increase in hospital morbidity in the South region, there was a moderate increase in the Midwest region and a decrease in hospital morbidity in the North region.

From the year 2011 there was a sudden drop in the rate of hospital morbidity in all regions except the South, where rates continued to increase in the years 2011 and 2012 (see Graph 2).

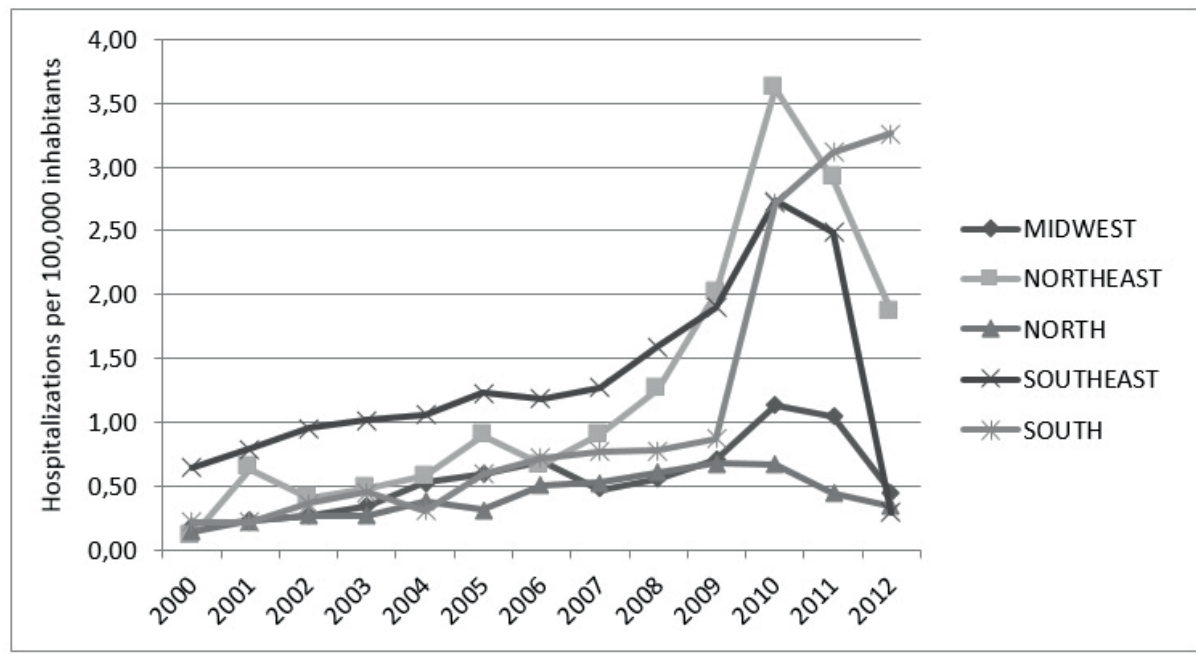

Graph 2. Hospital Morbidity rate from thyroid cancer by region of Brazil between 2000 and 2012. 
There was an increase in the average mortality rate of $35 \%$ over the studied period (see Graph 3 ). Among females, the average mortality rate was 0.39 deaths $/ 100,000$ inhabitants, higher than in males, with 0.19 deaths per 100,000 inhabitants. Despite this difference in the mortality rates, both show similar growth.

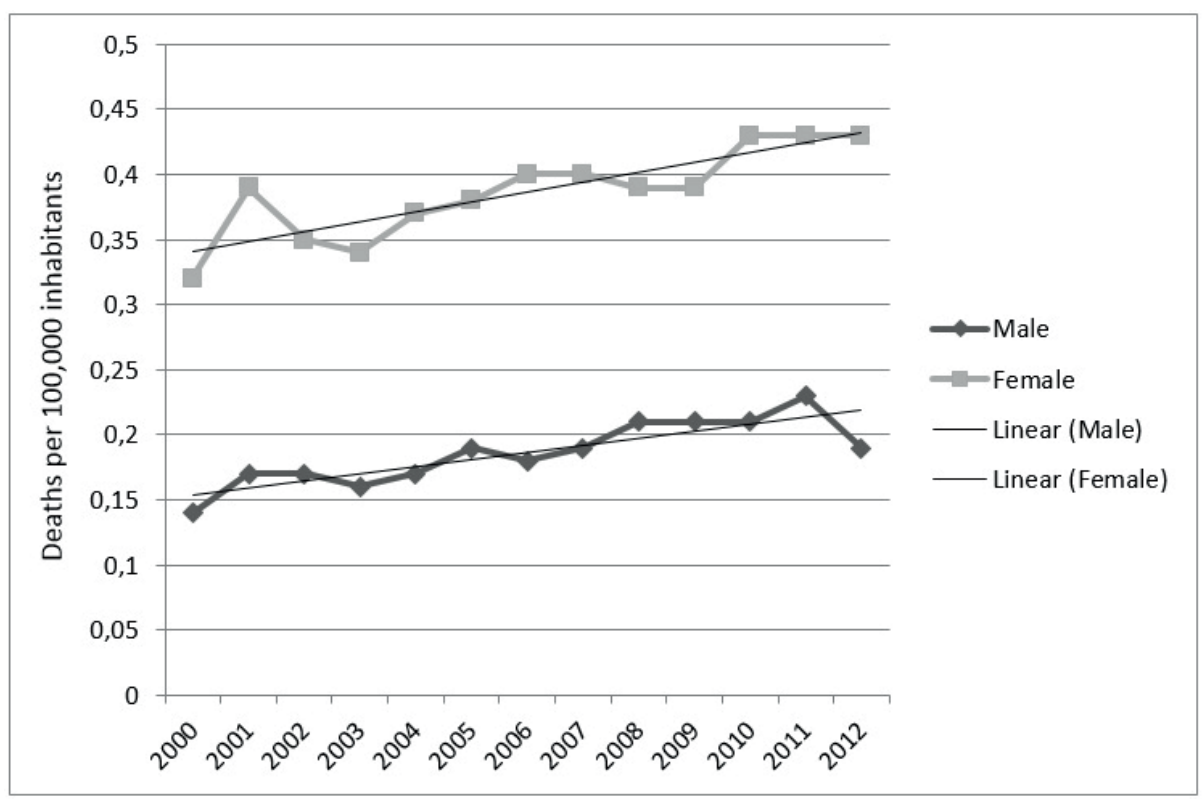

Graph 3. Thyroid cancer Mortality rate by gender in Brazil between 2000 and 2012.

From Graph 4 it is possible to observe that, despite the fluctuations in mortality rates over the 13 years, the regions that showed the highest rates in 2000 continued to be the highest in 2012.

The Southern region was the region that continued to have the highest mortality rate over the years studied, showing an average rate of 0.37 deaths every 100,000 inhabitants. This was followed by the Southeast and Midwest with 0.29 deaths every 100,000 inhabitants. These two regions feature a linearity on the values of rates over the 13 years, although in the Midwest region there was a moderate variation in rates when tested year after year.

The Northeast region has a high intermediate mortality rate, with an average of 0.26 deaths every 100,000 inhabitants and it was the region with the highest variation in this ratio over the 13 years. There was also an increase in mortality in the North region but it was the region with the lowest rates; an average of 0.18 deaths for every 100,000 inhabitants (see Graph 4).

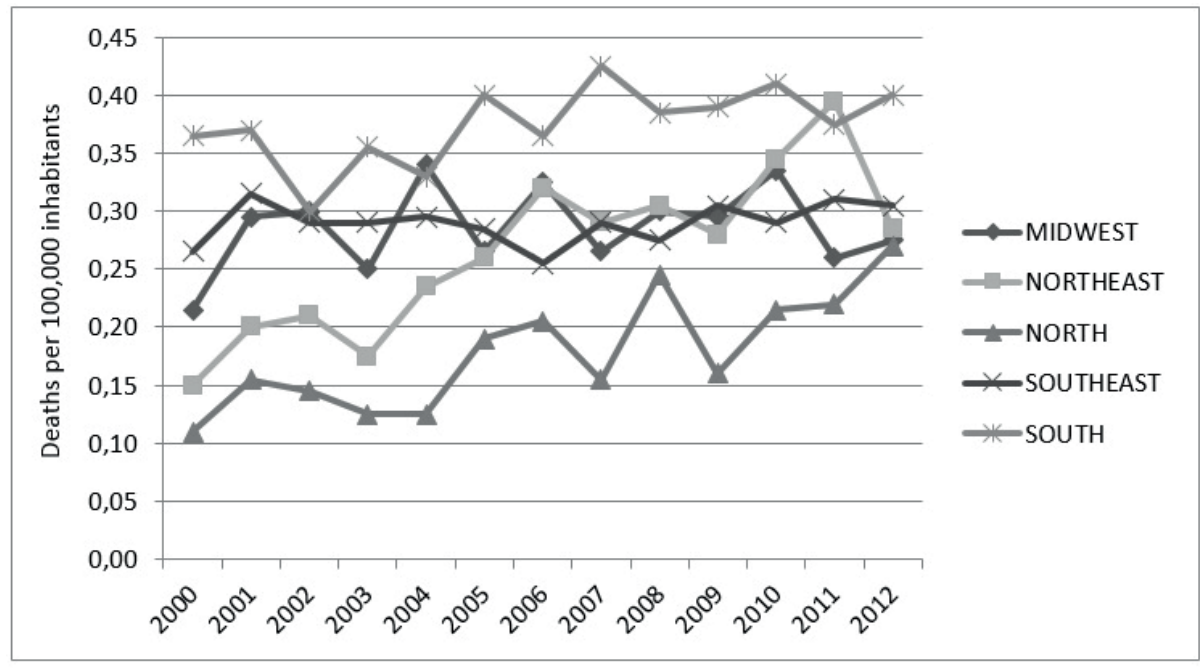

Graph 4. Thyroid cancer Mortality rate by region of Brazil between 2000 and 2012. 


\section{DISCUSSION}

In this study, we found a high rate of hospital morbidity from thyroid cancer between 2000 and 2012 . Curiously, the hospital morbidity rate reported in this study, which identified 0.55 cases for men and 2.64 for women per 100,000 inhabitants, was lower than the estimate for $2006^{16}$, with an expected 1.34 male cases and 6.3 female cases (per 100,000 inhabitants).

The highest hospital morbidity and mortality rates among women corroborate the literature, as we found incidence and mortality rates especially higher in women ${ }^{9,16}$.

Furthermore, we found that the majority of the thyroid cancer cases in Brazil are follicular or papillary (corresponding to approximately $93 \%$ of the cases). This is also in line the literature, which reported that $94 \%$ of the types of TC are either papillary or follicular ${ }^{7,8}$.

To our knowledge, this is the first study to report hospital morbidity and mortality rates by region. However, a study in the United States ${ }^{21}$ also found a difference in the rates of morbidity and mortality for thyroid cancer among the regions of the country.

Specifically for mortality, this study showed an increase in the rates, with an average of 0.19 cases per 100,000 male inhabitants and 0.39 female cases. These findings are different from previous investigations, which reported a fall in mortality in both genders between 1980 and 20108.

Findings regarding education, consumption of alcohol and tobacco and family history of cancer are not entirely clear as most of these variables had a large number of missing data. Although other studies also identified a connection between the thyroid cancer and education ${ }^{22}$, ethnicity ${ }^{26,27}$, history of consumption of drink and tobacco ${ }^{25}$, they remain controversial, because the mechanisms linking these factors to the onset of the disease remain unknown. The family history of cancer was reported in another study, however, the results were not statistically significant ${ }^{22}$ and without any prognostic value ${ }^{26}$.

Two important aspects can explain the increased rate of hospital morbidity. One is the improvement in the reporting of chronic diseases ${ }^{27}$ and access to health services in Brazil ${ }^{28}$. Another is changing lifestyle and nutritional habits, increasing exposure to risk factors such as exposure to ionizing radiation, reduced intake of iodine ${ }^{13}$, and possibly excess iodine intake ${ }^{29}$. Furthermore, obesity can contribute to the increase in cases of cancer, especially in women ${ }^{23}$.

Increased hospital morbidity from 2008 can be explained by the dissemination of diagnostic practices, which is supported by other research, moreover, another analysis showed that exposure to radiation to the head and neck, a personal history of cancer in the thyroid associated with other risk factors such as age, ethnicity, lifestyle, can lead to an increased chance of cancer onset ${ }^{9}$.

Regarding mortality, improvement in reporting of cases can also explain the increase in this rate. Another factor that potentially contributes to the increase in deaths is the possible lack of quality in health care, which can lead to delays in diagnosis and access to early treatment, leading to increased mortality.

A possible explanation for the high mortality rate in the South region is a result of the region's population, which is mostly European. The incidence of thyroid cancer in European countries has increased ${ }^{8}$, and as noted, most of the cases occur in Caucasians. However, in the same study, mortality in these countries is decreasing ${ }^{8}$ while in Brazil it is growing. This can probably be explained by the differences in health care between European countries and Brazil.

Moreover, the lifestyle of the population in the south of Brazil, contribute to this increase. Another factor is the human development index of the southern region, with consequent possible better access to health services, a factor that may be associated with more thyroid cancer diagnoses ${ }^{22}$.

The opposite can explain the mortality rate in the North, as the region has a predominantly indigenous population who account for only $0.2 \%$ of cases.

The predominance of the age group of 40-49 years in cases of thyroid cancer may be explained by the relationship between lifestyle habits, high BMI and 
excessive production of thyroid hormones. During the reproductive period, there is an increase in reproductive hormones, that may increase levels of TSH (thyroid stimulating hormone), which can lead to a thyroid hyperplasia, possibly cancer ${ }^{29}$. Through animal studies, it has been observed that chronic stimulation of the thyroid by increasing the TSH is associated with increasing frequency of thyroid cancer $^{15,30}$.

This study has some limitations, such as the use of secondary data and its dependence on public domain databases, leading to a possible underestimation or even overestimation of the reported rates. Data in This limitation made it impossible to collect data on incidence, as these data of thyroid cancer are not available in DATASUS and in RHC are from hospital admissions, which could lead to another bias, because an individual can be hospitalized more than once during the year.

Another limitation is the high number of records without further information. This demonstrates, a flaw in the filing of medical records, questionnaires and/or death certificates, or the export of data to the platforms. The lack of such data undermines the study because the concrete analysis of certain variables important for epidemiological surveys is not possible.

Despite these limitations, this study allows us to analyze the evolution of thyroid cancer in Brazil, and adds to the literature by comparing the regions and evaluates the characteristics of cases of thyroid cancer. If these findings are associated with more studies, they may help to establish the causes underlying the increase in cases and deaths from TC to support the development and implementation of more effective preventive measures.

\section{CONCLUSION}

From the results obtained in this study we can conclude that over the 13 years assessed, there was an increase in thyroid cancer morbidity and mortality in Brazil, with occurrence and deaths especially higher in females. The hospital morbidity rate for thyroid cancer has grown steadily. The mortality rate was constant during this period, especially in the Southern region where the highest rates can be found and in the North which has the lowest rates.

More research is needed regarding the role of risk factors in the appearance of thyroid cancer because the mechanisms underlying this association remain unknown. In addition, the implementation of health policies to minimize the risk of thyroid cancer and increase access to health care is needed in order to reduce the rates of hospital morbidity and mortality from TC. These policies should also include improving the quality of the secondary data to produce better epidemiological data which is so essential for the analysis of the health scenario and its determinants.

\section{REFERENCES}

1. Romagnoli, S, Moretti S, Voce P, Puxeddu

E. Targeted molecular therapies in thyroid carcinoma. Arq Bras Endocrinol Metab. 2009;53(9):1061-1073. doi: 10.1580/s000427302009000900002

2. Davies $L$, Welch HG. O aumento da incidência de câncer de tireóide nos Estados Unidos, 19732002. JAMA. 2006;295(17):2164-7. doi: 10.1001/jama.295.18.2164

3. American Cancer Society. Cancer Facts \& Figures 2012. Atlanta: American Cancer Society; 2012

4. Hu N, Li ZM, Liu JF, Zhang ZZ, Wang LS. An overall and dose-response meta-analysis for thyrotropin and thyroid cancer risk by histological type. Oncotarget. 2016;7(30):47750-47759. doi: 10.18632 /oncotarget. 10282

5. União Internacional Contra O Câncer. TNM - Classification of Malignant Tumours. 6 ed. Traduzido e publicado pelo INCA. Washington: John Wiley \& Sons; 2002

6. Degroot LJ, Larsen PR, Hennemann G. The Thyroid And Its Diseases. 6th ed. New York: Churchill Livingstone; 1996 
7. Golbert L, Wajner SM, Rocha AP, Maia AL, Gross JL. Carcinoma Diferenciado de Tireóide: Avaliação Inicial e Acompanhamento. Arq Bras Endocrinol Metab. 2005;49(5):701-710. doi: 10.1590/ S0004-27302005000500010. Portuguese

8. Guimarães RM, Muzi CD, Parreira VG, Santos RD, Sampaio JRC. Evolution of thyroid cancer mortality in adults in Brazil. Arq Bras Endocrinol Metab. 2013;57(7):538-544. doi: 10.1590/ S0004-27302013000700007

9. Coeli CM, Brito AS, Barbosa FS, Ribeiro $M G$, Sieiro APAV, Vaisman M. Incidência e Mortalidade por Câncer de Tireoide no Brasil.

Arq Bras Endocrinol Metab. 2005;49(4):503-509. doi: 10.1590/S0004-27302005000400006.

Portuguese

10. larc. WHO. GLOBOCAN 2012 [Internet]. 2015 [cited 21 mar. 2015]. Available from: http:// globocan.iarc.fr/Default.aspx

11. Cardis E, Howe G, Ron E, Bebeshko V, Bogdanova T, Bouville $A$ et al. Cancer consequences of the Chernobyl accident: 20 years on. J Radiol Prot. 2006;26(2): $127-40$. doi: 10.1088/0952$4746 / 26 / 2 / 001$

12. Kitahara CM, Platz EA, Freeman LE, Hsing AW, Linet MS, Park $Y$ et al. Obesity and thyroid cancer risk among U.S. men and women: a pooled analysis of five prospective studies. Cancer Epidemiology Biomarkers Prev. 2011 ;20(3):464-72. doi: 10.1 158/1055-9965.EPI-10-1220

13. Ward LS, Graf H. Câncer da Tiróide: Aumento na Ocorrência da Doença ou simplesmente na sua Detecção? Arq Bras Endocrinol Metab. 2008;52(9):1515-1516. doi: 10.1590/S000427302008000900018. Portuguese

14. Burgess JR, Tucker P. Incidence trends for papillary thyroid carcinoma and their correlation with thyroid surgery and thyroid fineneedle aspirate cytology. Thyroid. 2006; 16(1):47-53. doi: $10.1089 /$ thy. 2006.16 .47

15. Haselkorn T, Bernstein L, Preston-Martin S, Cozen W, Mack WJ. Descriptive epidemiology of thyroid cancer in Los Angeles County, 1972-1995.
Cancer Causes Control. 2000; 11 (2):163-70

16. Brito AS, Coeli CM, Barbosa FS, Caetano $R$, Santos MO, Vaisman M. Estimates of thyroid cancer incidence in Brazil: an approach using polynomial models. Cad. Saúde Pública.

2011 ;27(7): 1441 - 1444. doi: 10.1590/S0102$311 \times 2011000700019$

17. Aquino R et al. Estudos Ecológicos: Desenho de Dados Agregados. In: Barreto ML, Filho NA, Veras RP, Barata RB. Epidemiologia e Saúde: Fundamentos, Métodos, Aplicações. Rio de Janeiro: Guanabara Koogan; 2012. P. 175-184. Portuguese

18. Mota E, Carvalho DMT. Sistemas de Informação em Saúde. In: Rouquayrol MZ, Gurgel M.

Epidemiologia e Saúde. 6. ed. Rio de Janeiro: MEDSI; 201 1. P. 605-627. Portuguese

\section{Silva GAE, Teixeira MTB, Guerra MR.}

Epidemiologia do Câncer. In: Almeida Filho, Barreto N, Lima M. Epidemiologia e Saúde: Fundamentos, Métodos, Aplicações. Rio de Janeiro: Guanabara Koogan, 2012. P. 501-513. Portuguese

20. Brasil. Ministério da Saúde. DATASUS: SIM-Sistema de Informações de Mortalidade [Internet]. 2008 [cited 15 abr. 2015]. Available: http://www2.datasus.gov.br/DATASUS/index. php? area $=060701$. Portuguese

21. Mitchell I, Livingston EH, Chang AY, Holt S, Snyder WH, Lingvay I,. Trends in thyroid cancer demographics and surgical therapy in the United States. Surgery. 2007;1 42(6):823-828. doi: 10.1016/i.surg.2007.09.011

22. Cordioli MICV, Canalli MHBS, Coral $M H C$. Increase incidence of thyroid cancer in Florianopolis, Brazil: comparative study of diagnosed cases in 2000 and 2005. Arq Bras Endocrinol Metab. 2009;53(4):453-460. doi: $10.1590 /$ S0004-27302009000400011

23. Pellegriti $G$, Frasca $F$, regalbuto $C$, Squarito $S$, Vigneri R. Worldwide Increasing Incidence of Thyroid Cancer: Update on Epidemiology and Risk Factors. Journal of Cancer Epidemiology. 2013:1 10. doi: $10.1155 / 2013 / 965212$ 
24. Sipos JA, Mazzaferri, EL. Thyroid Cancer

Epidemiology and Prognostic Variables. Clinical

Oncology. 2010;22(6):395-404. doi: 10.1016/i. clon.2010.05.004

25. Rossing MA, Cushing KL, Voigt LF, Wicklund $K G$, Daling JR. Risk of papillary thyroid cancer in women in relation to smoking and alcohol consumption. Epidemiology. 2000;1 1 (1):49-54

26. Pellegriti G, Scollo $C$, Lumera $G$, Regalbuto C, Vigneri R, Belfiore A. Clinical Behavior and Outcome of Papillary Thyroid Cancers Smaller than $1.5 \mathrm{~cm}$ in Diameter: Study of 299 Cases. The Journal of Clinical Endocrinology \& Metabolism. 2004;89(8):3713-3720. doi: 10.1210/ic.2003031982

27. Teixeira MG, pena GO, Risi JB, Penna ML, Alvim MF, Moraes JC et al. Seleção das doenças de notificação compulsória: critérios e recomendações para as três esferas de governo. Informe Epidemiológico do Sus. 1998;7(1):7-28, 1998. doi: $10.5123 / \mathrm{s} 0104-16731998000100002$. Portuguese

28. Andrade MV, Noronha KVMS, Menezes RM, Souza MN, Reis CB, Martins DR et al. Desigualdade socioeconômica no acesso aos serviços de saúde no Brasil: um estudo comparativo entre as regiões brasileiras em 1998 e 2008. Econ. Apl. 2013;17(4):623-645. doi: 10.1590/S141380502013000400005 . Portuguese

29. Dal Maso L, Bosetti C, La Vecchia C, Franceschi S. Risk factors for thyroid cancer: an epidemiological review focused on nutritional factors. Cancer Causes \& Control. 2008;20(1):7586. doi: $10.1007 / \mathrm{s} 10552-008-9219-5$

30. Boelaert K, Horacek J, Holder RL, Watkinson JC, Sheppard MC, Franklyn JA. Serum thyrotropin concentration as a novel predictor of malignancy in thyroid nodules investigated by fine-needle aspiration. J Clin Endocrinol Metab. 2006;91(11):4295-4301. doi: 10.1210/jc.20060527 